\title{
EL PROYECTO DE LEY DE BASES DE LA ADMINISTRACION LOCAL
}

$352(094)$

por

Juan-Luis de Simón Tobalina

SUMARIO: I. ANTECEDENTES HISTORICOS. - II. SITUACION CAOTICA ACTUAL.-III. LA «TRANSICION" EN NUESTRO REGIMEN LOCAL. - IV. NATURALEZA DE LA NUEVA LEY. V. ESTRUCTURA. - VI. TENDENCIAS DOCTRINALES DOMINANTES.-VII. CONFIGURACION DE LAS ENTIDADES LOCALES: 1. ENTIDADES MUNICIPALES. 2. ENTIDADES PROVINCIALES. 3. DisPOSICIONES COMUNES A MUNICIPIOS Y PROVINCIAS.-VIII. HACIA UN TRATAMIENTO UNITARIO DEL REGIMEN ADMINISTRATIVO.-IX. CONCLUSION.

\section{ANTECEDENTES HISTORICOS}

El punto de partida de la evolución legislativa de nuestro Régimen local es la Constitución de Cádiz de 1812. Aunque en su discurso preliminar se lee que «nada ofrece la Comisión en su proyecto que no se haya consignado del modo más auténtico en los diferentés cuerpos de la legislación española», y el CONDE DE TORENO y don Eduardo DE HINOJOSA corroborasen este criterio al subrayar el sentido histórico de las Cortes de Cádiz y su afán de restaurar las antiguas libertades municipales viciadas en el siglo xv y, más aún, pos- 
teriormente, es indudable la honda influencia que ejerció sobre nuestros doceañistas "el espíritu de la época", tan dominada-como hacía notar don Adolfo González PoSADA-por los principios de gobierno mediante el engranaje nada disimulado de todas las instituciones locales en una jerarquía mecánica, según un sistema de subordinación, que contiene el germen de la futura censura administrativa centralizada, uniforme y simétrica, y las condiciones para un desarrollo del espíritu burocrático.

Al regresar al trono FeRnando VII en 1814, fue declarada sin efecto la obra constitucional de las Cortes de Cádiz, restaurándose el absolutismo con todas sus consecuencias. Pero en 1820 resurgen el régimen constitucional y la revisión del Régimen local, si bien por breve espacio de tiempo, pues en 1823, gracias a la intervención de los Cien Mil Hijos de San Luis, resucita nuevamente el absolutismo. Sólo a partir de la Constitución de 1837 se va consolidando lentamente, aunque con reacciones autoritarias, el sistema constitucional que se refleja en las sucesivas Constituciones-de 1845, de 1869 y de 1876-y leyes municipales y provinciales que desarrollan las respectivas normas constitucionales sobre Régimen local. Entre la Constitución y las leyes articuladas de Régimen local no se daban entonces leyes de Bases, sino que, directamente, se desarrollaban los preceptos constitucionales en leyes articuladas; pero a partir del bienio progresista de 1854 se cambió el sistema al preceder a las leyes articuladas leyes de Bases, las cuales van, en realidad, dirigidas no a la comunidad política directamente, es decir, a los ciudadanos para regir su conducta, sino al Gobierno, para que dicte una ley articulada ajustada a dichas Bases y de general aplicación en todo el territorio nacional.

A esta fase de leyes de Bases corresponde la de Gobierno y Administración provincial y municipal de 14 de diciembre de 1855 , en desarrollo de la cual se dictó la Ley municipal de 5 de julio de 1856 . Pero ese mismo año importantes acontecimientos, a los que no fue ajena la intervención militar, al acabar con el Gobierno del bienio progresista, determinaron el total fracaso de la obra de las Constituyentes, restableciéndose el imperio de las leyes anteriores sobre organización y atribuciones de Ayuntamientos, Diputaciones Provinciales y Consejos Provinciales. Comienza así una nueva etapa en el proceso histórico legislativo de nuestro Régimen local, en el cual «van a dejarse sentir contradictoriamente-como dice PoSADA-los 
influjos del dogmatismo de la Unión liberal y del moderantismo reaccionario, que prepara con su política exclusivista la Revolución de 1888». En la legislatura de 1893-94 se intentó infructuosamente una nueva refundición de las leyes provinciales y municipales, mediante unas bases que aprobó el Senado para una Ley Orgánica de Administración y Régimen de los Municipios y de las Provincias.

Figura descollante de la reforma de nuestro Régimen local fue don Antonio Maura, quien, como Ministro de la Gobernación, presentó al Senado el 26 de mayo de 1903 un importante proyecto de Ley estableciendo las bases para la reforma de la Administración local, cuya discusión parlamentaria llegó a iniciarse, pero fue suspendida al sobrevenir un cambio de situación ministerial. Con un Gobierno liberal en el Poder, el Ministro de la Gobernación CoNDE DE Romanones presentó el proyecto de 9 de enero de 1906, que, según se advertía en el preámbulo, era "reproducción, en sus líneas esenciales, del proyecto de reforma municipal sometido al Parlamento en 1902». Las oposiciones atacaron violentamente el proyecto, que no llegó a convertirse en ley.

El gran debate-como Tussel lo llama-surge cuando Maura, de nuevo en el Poder, presenta el trascendental proyecto de 1907, que durante dos años de discusión parlamentaria suscitó el mayor número de enmiendas y de discursos de que ha sido objeto en nuestro Parlamento un proyecto de ley. Con razón ha dicho don Adolfo PoSADA que el debate fue "solemne y apasionado". La crisis de octubre de 1909, a consecuencia de la semana sangrienta de Barcelona, determinó el fracaso de dicho proyecto cuando ya se había entrado en su fase final.

La vuelta al sistema de ley de Bases tuvo lugar cuando el Ministro BARRoso-en un Gobierno presidido por CANALEJAS-leyó ante el Congreso de los Diputados el proyecto de Ley de Bases de Régimen local de 15 de octubre de 1912, cuya elaboración y presentación a las Cortes fue una de las condiciones impuestas por los liberales a su propio líder y jefe de partido, CANALEJAS, para la aprobación del proyecto de Mancomunidades provinciales presentado al Congreso de los Diputados en mayo de 1912 por el propio Ministro Barroso. La discusión parlamentaria de dicho proyecto quedó interrumpida al ser asesinado CaNALEJas, en noviembre del mismo año 1912. Entre dicha fecha y el establecimiento de la dictadura de septiembre de 1923 cabe también recordar el proyecto de Ley de Bases presen- 
tado por el Ministro BuRgos MAzo en 1919 para regular la vida municipal de las grandes ciudades, que no llegó a discutirse.

Durante la dictadura de PRIMO DE RIVERA se promulgaron autoritariamente $\mathrm{y}$, por tanto, sin atenerse a normas constitucionales ni a ley de Bases, alguna aprobada por el Poder legislativo (entonces inexistente), el Estatuto municipal de 8 de marzo de 1924 y el Estatuto provincial de 20 de marzo de 1925. La República instaurada el 14 de abril de 1931 volvió al correcto sistema de las leyes de Bases, aprobándose la de 9 de junio de 1935 (que constaba de 28 bases), articulada en la Ley municipal aprobada por Decreto de 31 de octubre de 1935. En ella se continúa la línea autonómica iniciada con el Estatuto de Calvo Sotelo, cuya característica más elocuente es la plena efectividad de los acuerdos municipales, sin que contra ellos pueda recurrirse, salvo excepcionalmente, en la vía gubernativa y sí sólo en la vía jurisdiccional.

El carácter democrático del gobierno municipal consagrado en la Ley de 1935 era incompatible con el régimen autoritario implantado por el General Franco, que, desde su establecimiento, dejó sin efecto las normas democráticas de la expresada Ley del 35, aprobada por las Cortes republicanas. La Ley de Bases de Régimen local de 17 de junio de 1945 otorgaba a las Corporaciones locales el carácter de órganos rectores enmarcados dentro del sistema autoritario del gobierno del Estado, y fue desarrollada en la Ley articulada aprobada por Decreto de 16 de diciembre de 1950, la cual, tras las reformas de las anteriores Bases introducidas por la Ley de 3 de diciembre de 1953, adquirió forma definitiva en el texto refundido aprobado por Decreto de 24 de junio de 1955. Es nota que merece destacarse la relativa aceptación del carácter autonómico iniciado en 1924 que pone de relieve el artículo 361 de dicha Ley, al decir que: "los actos y acuerdos de las autoridades y Corporaciones locales serán inmediatamente ejecutivos cuando no requieran aprobación o autorización gubernativa, sin perjuicio de los recursos que la Ley establece». Esa referencia a la posible exigencia de la aprobación o autorización gubernativa sólo tiene efectividad en casos excepcionales, mientras en la generalidad de ellos es aplicable el artículo 386 , a tenor del cual: "Los actos y acuerdos de las autoridades y Corporaciones locales, con excepción de aquellos a que la ley asigna otro recurso de naturaleza especial, causarán estado en la vía gubernativa y podrán ser objeto de recurso contencioso-administrativo ante el Tribunal Provincial». 
influjos del dogmatismo de la Unión liberal y del moderantismo reaccionario, que prepara con su política exclusivista la Revolución de 1888». En la legislatura de 1893-94 se intentó infructuosamente una nueva refundición de las leyes provinciales y municipales, mediante unas bases que aprobó el Senado para una Ley Orgánica de Administración y Régimen de los Municipios y de las Provincias.

Figura descollante de la reforma de nuestro Régimen local fue don Antonio MaURA, quien, como Ministro de la Gobernación, presentó al Senado el 26 de mayo de 1903 un importante proyecto de Ley estableciendo las bases para la reforma de la Administración local, cuya discusión parlamentaria llegó a iniciarse, pero fue suspendida al sobrevenir un cambio de situación ministerial. Con un Gobierno liberal en el Poder, el Ministro de la Gobernación CONDE DE ROMANONES presentó el proyecto de 9 de enero de 1906, que, según se advertía en el preámbulo, era "reproducción, en sus líneas esenciales, del proyecto de reforma municipal sometido al Parlamento en 1902". Las oposiciones atacaron violentamente el proyecto, que no llegó a convertirse en ley.

El gran debate-como Tussel lo llama-surge cuando MAURA, de nuevo en el Poder, presenta el trascendental proyecto de 1907, que durante dos años de discusión parlamentaria suscitó el mayor número de enmiendas y de discursos de que ha sido objeto en nuestro Parlamento un proyecto de ley. Con razón ha dicho don Adolfo PoSADA que el debate fue "solemne y apasionado». La crisis de octubre de 1909, a consecuencia de la semana sangrienta de Barcelona, determinó el fracaso de dicho proyecto cuando ya se había entrado en su fase final.

La vuelta al sistema de ley de Bases tuvo lugar cuando el Ministro BARROSO-en un Gobierno presidido por CANALEJAS-leyó ante el Congreso de los Diputados el proyecto de Ley de Bases de Régimen local de 15 de octubre de 1912, cuya elaboración y presentación a las Cortes fue una de las condiciones impuestas por los liberales a su propio líder y jefe de partido, Canalejas, para la aprobación del proyecto de Mancomunidades provinciales presentado al Congreso de los Diputados en mayo de 1912 por el propio Ministro Barroso. La discusión parlamentaria de dicho proyecto quedó interrumpida al ser asesinado CaNALEJAS, en noviembre del mismo año 1912. Entre dicha fecha y el establecimiento de la dictadura de septiembre de 1923 cabe también recordar el proyecto de Ley de Bases presen- 
tado por el Ministro BuRgos MAzo en 1919 para regular la vida municipal de las grandes ciudades, que no llegó a discutirse.

Durante la dictadura de PRIMo DE RIVERA se promulgaron autoritariamente $\mathrm{y}$, por tanto, sin atenerse a normas constitucionales ni a ley de Bases, alguna aprobada por el Poder legislativo (entonces inexistente), el Estatuto municipal de 8 de marzo de 1924 y el Estatuto provincial de 20 de marzo de 1925. La República instaurada el 14 de abril de 1931 volvió al correcto sistema de las leyes de Bases, aprobándose la de 9 de junio de 1935 (que constaba de 28 bases), articulada en la Ley municipal aprobada por Decreto de 31 de octubre de 1935. En ella se continúa la línea autonómica iniciada con el Estatuto de Calvo Sotelo, cuya característica más elocuente es la plena efectividad de los acuerdos municipales, sin que contra ellos pueda recurrirse, salvo excepcionalmente, en la vía gubernativa y sí sólo en la vía jurisdiccional.

El carácter democrático del gobierno municipal consagrado en la Ley de 1935 era incompatible con el régimen autoritario implantado por el General Franco, que, desde su establecimiento, dejó sin efecto las normas democráticas de la expresada Ley del 35, aprobada por las Cortes republicanas. La Ley de Bases de Régimen local de 17 de junio de 1945 otorgaba a las Corporaciones locales el carácter de órganos rectores enmarcados dentro del sistema autoritario del gobierno del Estado, y fue desarrollada en la Ley articulada aprobada por Decreto de 16 de diciembre de 1950, la cual, tras las reformas de las anteriores Bases introducidas por la Ley de 3 de diciembre de 1953, adquirió forma definitiva en el texto refundido aprobado por Decreto de 24 de junio de 1955. Es nota que merece destacarse la relativa aceptación del carácter autonómico iniciado en 1924 que pone de relieve el artículo 361 de dicha Ley, al decir que: «los actos y acuerdos de las autoridades y Corporaciones locales serán inmediatamente ejecutivos cuando no requieran aprobación o autorización gubernativa, sin perjuicio de los recursos que la Ley establece». Esa referencia a la posible exigencia de la aprobación o autorización gubernativa sólo tiene efectividad en casos excepcionales, mientras en la generalidad de ellos es aplicable el artículo 386, a tenor del cual: "Los actos y acuerdos de las autoridades y Corporaciones locales, con excepción de aquellos a que la ley asigna otro recurso de naturaleza especial, causarán estado en la vía gubernativa y podrán ser objeto de recurso contencioso-administrativo ante el Tribunal Provincial». 
El cuerpo de normas de Régimen local 1950-1955 envejeció pronto, no sólo por efecto del fenómeno que ha sido llamado «aceleración de la historia", sino también por consecuencia de ser ya, en la época en que se promulgaron, abiertamente contrarias al proceso democrático predominante desde la terminación de la segunda guerra mundial en todo el occidente europeo. Era imprescindible, por tanto, una reforma del Régimen local aun dentro del sistema autoritario establecido. Cuando el General Franco expiraba-rigurosamente, la víspera de su muerte-las Cortes «orgánicas» aprobaron la Ley de Bases de Régimen local de 19 de noviembre de 1975, que apareció en el Boletín Oficial del Estado con la firma de Don Juan Carlos DE Borbón, Príncipe de España, en funciones de Jefe de Estado, y la de don Alejandro Rodríguez de Valcárcel y Nebreda, como Presidente de las Cortes Españolas. Dicha Ley de Bases suponía alguna apertura hacia la democracia al otorgar el voto a todos los vecinos, si bien con grave limitación de la presentación de candidatos, al encuadrar a éstos dentro de los tres cauces famosos que definían la llamada «democracia orgánica». Pero el nuevo régimen democrático español era difícilmente conciliable con dicha Ley, por lo que su articulación fue sólo parcial y fragmentaria en el texto articulado parcial aprobado por Real Decreto de 6 de octubre de 1977 (BOE de 26 de noviembre de 1977).

\section{SITUACION CAOTICA ACTUAL}

Resultado de esta evolución es que la legislación de Régimen local vigente es enteramente cabtica hasta extremos a que nunca se había llegado, y que en la maraña de normas dudosamente vigentes hay que acudir alternativamente al expresado texto fragmentario, al texto refundido de 1955, a la Ley de Elecciones locales y a una serie de disposiciones transitorias, provisionales, complementarias, etcétera, que hacen sumamente difícil la labor de Alcaldes, Concejales y funcionarios de la Administración local, y, por tanto, una fructífera Vida local.

Esta situación caótica se puso de relieve en la tabla de preceptos sobre Régimen local que continuaban vigentes o quedaban derogados que se inserta al final del texto articulado parcial. En esta desordenada tabla se mezcla la enumeración de las disposiciones dero- 
gadas con las vigentes y con las que rigen uen cuanto no se opongan al presente texto articulado", y se citan sin la menor sistematización, orden ni concierto las normas legales y reglamentarias relativas a todas las materias que se regulan en el texto articulado parcial, así como todas las demás materias de régimen local que han quedado fuera de dicho texto articulado. Tras una disposición del Reglamento de Población y Demarcación se cita otra relativa al de Contratación; después, otra relativa a funcionarios; seguidamente, otra nuevamente sobre la contratación, a la que sigue otra más referida a funcionarios o a organización y funcionamiento, etc. No se puede ofrecer una demostración más exacta de lo que es el caos cuando las cosas se hacen de cualquier manera. Se citan nada menos que 84 cuerpos legales o reglamentarios, desde leyes como la de Régimen local (texto articulado y refundido aprobado por Decreto de 24 de junio de 1955); la de 27 de diciembre de 1956, sobre ayuda familiar a funcionarios locales, y la de 12 de mayo de 1960, sobre Mutualidad Nacional de Previsión de la Administración Lo. cal, hasta Ordenes ministeriales como la de 5 de diciembre de 1973, que modifica la tabla de valoración de méritos en concursos de Cuerpos nacionales, entre otras muchas; $y$, a veces, nada definitivamente orientador sobre la vigencia o derogación de la Ley, Decreto u Orden ministerial que se menciona queda decidido, pues el texto correspondiente se limita a decir: "vigente en cuanto no se oponga al presente texto articulado", con lo cual queda al ejecutor de la Ley, Decreto $u$ Orden de que se trate la nada sencilla labor de estudiar cada precepto específico para saber si se opone o no al desdichado texto articulado parcial.

Añádase a lo dicho la circunstancia de que, con posterioridad al expresado texto articulado parcial de la Ley 41/1975, de Bases del Estatuto de Régimen local, se han promulgado importantes leyes y decretos, y muy especialmente la Ley de 17 de julio de 1978 (BOE del 21), de Elecciones locales, y el Decreto de 5 de abril de 1979, sobre creación del Ministerio de Administración Territorial, y se comprenderá hasta qué punto resultaba inaplazable la presentación a las Cortes de una nueva Ley de Bases de Régimen local que terminara con el presente caos y hasta qué punto las Cortes deben dar primacía a la discusión de dicho proyecto, cuya aprobación es indispensable para la normalización de la Vida local española. 


\section{LA «TRANSICION» EN NUESTRO REGIMEN LOCAL}

Si delicada era la transición en la vida del Estado del régimen autoritario que personalizó el General Franco al régimen democrático iniciado por la Ley de Reforma política aprobada en referéndum nacional el 15 de diciembre de 1976, no era mucho menos delicado el tránsito paralelo de nuestro Régimen local. Los criterios de reforma política que desde la segunda restauración de la Monarquía de noviembre de 1975 han prevalecido sobre los de ruptura, que defendían los partidos políticos más radicalizados, permitieron que durante los primeros años del nuevo régimen continuasen los Ayuntamientos y Diputaciones constituidos durante el régimen de FraNco. Urgía-si no se quería volver al establecimiento de Comisiones gestoras a las que se recurrió repetidas veces en anteriores añosla celebración de elecciones municipales y provinciales. Hubieran podido realizarse aplicando las respectivas leyes anteriores al régimen de FraNco, pero ello hubiera sido contrario al criterio implantado en la misma constitución de la elección del Congreso de los Diputados, atendiendo a «criterios de representación proporcional». Sabido es, en efecto, que en todos los países las elecciones municipales y las legislativas responden a análogos criterios de representación. El sufragio universal se implanta siempre en el área municipal simultáneamente a su implantación en el área del Estado. Así, en nuestra Patria, tanto para las Corporaciones locales como para el Congreso de los Diputados o Cámara Baja legislativa, a partir de la Ley de SAGASTA de 1890 . Y la Ley Electoral debida a don Antonio MAURA de 8 de agosto de 1907 se aplicó indistintamente para elecciones municipales, provinciales y generales. Ya el artículo $10^{\circ}$ de dicha Ley muestra este criterio unitario al expresar que: "Son electores para Diputados a Cortes y Concejales todos los españoles mayores de veinticinco años que se hallen en el pleno goce de sus derechos civiles y sean vecinos de un Municipio, en el que cuenten dos años al menos de residencia".

Lo que no se ha dado nunca es el caso de que se apruebe una Ley de Elecciones locales-al fin, Ley adjetiva-sin que una Ley de Régimen local $\longrightarrow$ una Ley municipal y una Ley provincial-establezcan la regulación orgánica correspondiente. Pero todavía es más grave el caso porque no sólo se contienen en dicha Ley de Elecciones locales normas de procedimiento electoral para Concejales y Diputados provinciales, sino que se establecen las normas para la cons- 
titución de las respectivas Diputaciones, se determina la forma de la elección de Alcaldes-"cuestión batallona», como la llamaba la exposición de motivos del Estatuto Municipal-, se regula la constitución de Comisiones permanentes en los Ayuntamientos de dos mil habitantes en adelante e incluso otros problemas de funcionamiento de las Corporaciones, como el relativo a la publicidad de las sesiones.

\section{NATURALEZA DE LA NUEVA LEY}

Dados los antecedentes expuestos parecía lógico esperar que la nueva Ley tuviera el carácter de Ley de Bases que diese nueva elaboración fundamental a nuestro Régimen local para su posterior desarrollo en la correspondiente ley articulada, sin perjuicio de abandonar en mayor o menor medida esta articulación a las comunidades locales constituidas y que se vayan constituyendo en lo sucesivo. Dicho de otro modo, el problema que se presentaba de modo inmediato era el de si esa Ley básica iba a servir para la redacción de una ley articulada general o si se dejaba a la iniciativa de cada Comunidad Autónoma la redacción de la que ha de aplicarse en su respectivo territorio general. La duda proviene del estudio comparativo entre los artículos 148 y 149 de la Constitución, que enumeran, respectivamente, las competencias que pueden asumir las Comunidades Autónomas y las materias sobre las cuales tiene el Estado exclusiva competencia (aunque el orden lógico sería el contrario; y no es este el menor defecto de nuestra Ley fundamental). El artículo 148 menciona entre las competencias de las Comunidades Autónomas: "Las alteraciones de los términos municipales comprendidos en su territorio $y$, en general, las funciones que correspondan a la Administración del Estado sobre las Corporaciones locales y cuya transferencia autorice la legislación sobre Régimen local». El artículo 149, por su parte, atribuye al Estado competencia exclusiva, entre otras materias, sobre las siguientes: «Las bases de régimen jurídico de las Administraciones públicas y del régimen estatutario de sus funcionarios, que, en todo caso, garantizarán a los administrados un tratamiento común ante ellas y el procedimiento administrativo común, sin perjuicio de las especialidades derivadas de la organización propia de las Comunidades Autónomas, legislación 
sobre expropiación forzosa, legislación básica sobre contratos y concesiones administrativas y el sistema de responsabilidad de todas las Administraciones públicas".

La exposición de motivos del Proyecto desarrolla de una manera no demasiado convincente el estudio de la naturaleza jurídica de la nueva Ley, entremezclándolo con el relativo al reparto de competencias sobre nuestro futuro Régimen local entre el Estado y las Comunidades Autónomas. Conviene reproducir su argumentación, que no tiene desperdicio: «La Ley por la que se aprueban las bases de la Administración local se dicta en cumplimiento del mandato implícito contenido en los artículos $148,1,2 .^{a}$, y $149,1,18$, de la Constitución. El artículo 149, 1, 18, del Texto constitucional establece como competencia exclusiva del Estado el establecimiento de 'las bases del Régimen jurídico de las Administraciones públicas', entre las que, como es obvio, se inserta la denominada Administración local. Por otra parte, el artículo 148, 1, 2. ${ }^{\text {, }}$, prevé la posibilidad de que 'las Comunidades Autónomas ejerzan competencias que corresponden a la Administración del Estado en relación con las Corporaciones locales, siempre que lo autorice la legislación sobre régimen local'. [...] La Ley se limita a regular los aspectos más importantes del Régimen local. Por tal razón, en modo alguno agota la regulación sobre la materia. En efecto, cuestiones tan importantes, entre otras, como la posible creación de Comarcas y otras agrupaciones de $\mathrm{Mu}$ nicipios; la alteración de términos municipales; el establecimiento de un régimen especial para los pequeños Municipios; procedimiento para la creación y supresión de Municipios y creación de Entidades locales menores; o la regulación de las formas de gestión directa o indirecta de los servicios públicos locales, se remiten a la legislación específica que puedan dictar las Comunidades Autónomas. Corresponderá también a dichas Comunidades desarrollar legislativamente aquellas cuestiones, ciertamente numerosas, que tan sólo se esbozan o perfilan en la Ley, así como dictar cuantas disposiciones sean necesarias para su aplicación".

Para comprender el alcance de este deslinde de competencias es necesario contemplar lo que se dice sobre esta materia en los Estatutos de Autonomía aprobados hasta la fecha. El Estatuto de Autonomía para el País Vasco, aprobado por referéndum de las Provincias de Alava, Guipúzcoa y Vizcaya el día 25 de octubre de 1979, dispone en su artículo 10 que «la Comunidad Autónoma del País Vasco tiene competencia exclusiva, entre otras materias, en las siguientes: 
Régimen local y Estatuto de los Funcionarios del País Vasco y de su Administración local, sin perjuicio de lo establecido en el artículo 149, 1, 18, de la Constitución». El Estatuto de Autonomía de Cataluña, aprobado por referéndum de las Provincias de Barcelona, Gerona, Lérida y Tarragona el 25 de octubre de 1979, atribuye en su artículo 9.' a la Generalidad de Cataluña competencia exclusiva, entre otras materias, sobre las siguientes: «8. Régimen local, sin perjuicio de lo que dispone el número $18 \mathrm{del}$ apartado 1 del artículo 149 de la Constitución. Alteraciones de los términos municipales y denominación oficial de los Municipios y topónimos». El Estatuto de Autonomía de Galicia, aprobado en referéndum de las Provincias de La Coruña, Lugo, Orense y Pontevedra el 21 de diciembre de 1980, confiere competencia exclusiva a la Comunidad Autónoma gallega, entre otras materias, sobre: «2. Organización y Régimen jurídico de las Comarcas y Parroquias rurales como Entidades locales propias de Galicia; alteraciones de términos municipales comprendidos dentro de su territorio, y, en general, las funciones que sobre el Régimen local correspondan a la Comunidad Autónoma, al amparo del artículo 149, 1, 18, de la Constitución y su desarrollo». Una aplicación específica de la competencia atribuida a la Comunidad Autónoma gallega se contiene en el párrafo 2 de la Disposición final segunda del anteproyecto, al decir que: "La Parroquia rural gallega se regirá por su derecho consuetudinario y por las disposiciones que dicte la Comunidad Autónoma de Galicia, de acuerdo con lo previsto en su Estatuto de Autonomía y en la presente Ley». Y una nueva precisión respecto a la dualidad de gobierno del Estado y Comunidades Autónomas, en relación con la competencia para dictar las disposiciones de desarrollo de la Ley Básica de Administración local que elaboran en estos momentos las Cortes Generales en torno al proyecto presentado por el Gobierno, se contiene en la Disposición final tercera del Proyecto, al decir que: «Las competencias que esta Ley atribuye expresamente a las Comunidades Autónomas corresponderán a la Administración del Estado en las Provincias y Territorios donde no se hubieran constituido aquéllas».

A nuestro juicio, la aplicación de la Disposición final de que acabamos de hacer mérito, en relación con los Estatutos autonómicos aprobados, deja abierta la puerta a posibles conflictos de competencia que correspondería resolver al Tribunal Constitucional. Afortunadamente, el artículo 137 del Proyecto crea el Consejo de las Cor- 
poraciones Locales de España como órgano de relación, coordinación y colabóración de la Administración del Estado con las Entidades localess. Su órgano de gobierno será el Pleno, que estará integrado por representantes de la Administración del Estado, de las Comiunidades Autónomas y de las Entidades locales. La Secretaría drél Consejo tendrá su sede en el Instituto de Estudios de Admi'nistración Local.

En realidad, el problema fundamental de la aplicabilidad de esta Ley en todo el territorio del Estado intenta resolverse en el artículo 1., que, copiado literalmente, dice así: «1. Las Entidades locales se regirán: a) por la presente Ley; b) por la legislación del Estado, en los casos expresados previstos en la presente Ley o en otras Leyes especiales; c) por la legislación que dicten las Comunidades Autónomas en desarrollo y ejecución de la presente Ley, y en virtud de lo dispuesto en sus respectivos Estatutos; d) por lo establecido en las Ordenanzas y Reglamentos específicos de cada Entidad; y 2. La legislación del Estado tendrá carácter supletorio respecto de todas las disposiciones legales y reglamentarias a que se refieren los apartados c) y d) del número anterior».

\section{ESTRUCTURA}

El nuevo Proyecto de Ley de Bases de la Administración local es, en realidad, una Ley articulada, si bien breve y concisa, en relación con la de 1955 (Texto refundido de 24 de junio de dicho año). Constaba ésta de 796 artículos, y el actual Proyecto, de 137. Si no se modifica su estructura en la elaboración parlamentaria estará dividida la nueva Ley en un Título preliminar y cinco Títulos: Primero. De las Entidades municipales.-Segundo. De las Entidades provinciales.-Tercero. Disposiciones comunes a las Corporaciones locales.Cuarto. De las Haciendas locales.-Quinto. Relaciones de las Entidades locales con la Administración del Estado y las Comunidades Autónomas. Los Títulos se dividen en capítulos; éstos, en secciones, y éstas, en artículos, hasta un total, según queda dicho, de 137. A continuación se insertan tres Disposiciones finales, cuatro transitorias y una derogatoria.

El plan del Proyecto está inspirado en la Ley de 1955, si bien no se adopta la división de ésta en Libros, y sólo dentro de éstos en 
Títulos, capítulos, secciones y artículos. Pero el plan es sustancialmente el mismo, a saber: organización y administración de las Entidades municipales; organización y administración de las Provincias (o de las Entidades provinciales, como dice el Proyecto); disposiciones comunes a las Corporaciones locales (o, como decría le Ley del 55, a la organización y la administración de Municipios'y Provincias) y Haciendas locales. El Proyecto añade un nuevo Tí-' tulo ("Libro», hubieran dicho los redactores de la Ley de 1955), dedicado a la relación de las Entidades locales con la Administración del Estado y las Comunidades Autónomas.

Pero esto no entraña ninguna novedad, pues, en desarrollo de las Bases 46 y 47 de la Ley 41/1975, de Bases del Estatuto del Régimen local, el Texto articulado parcial aprobado por Real Decreto de 6 de octubre de 1977 añade dos capítulos: el cuarto, titulado «Cooperación del Estado a la realización de las competencias locales», y el quinto, que lleva por epígrafe «Colaboración de las Entidades locales a la realización de servicios del Estado». Sólo se añade la obligada referencia a las Comunidades Autónomas. En suma, podemos decir que desde la primera Ley, que da un tratamiento unitario al régimen municipal y régimen provincial, es decir, desde la Ley tan repetidamente citada de 1950-1955, se ha consolidado una estructura que podemos considerar, en cierto modo, clásica del ordenamiento legal de nuestros Municipios y Provincias.

\section{TENDENCIAS DOCTRINALES DOMINANTES}

La lectura atenta y reposada de la exposición de motivos que acompaña al Anteproyecto redactado por el Gobierno nos revela sus principios inspiradores. La primera preocupación de los redactores del texto presentado a las Cortes ha sido la de afirmar la autonomía de las Entidades locales para la gestión de sus intereses, rectificando decididamente el signo centralista que durante todo el siglo XIX $\mathrm{y}$ las dos primeras décadas del $\mathrm{xx}$ tuvo nuestro régimen local. Con razón se hace notar en la referida exposición de motivos que si bien el Estatuto Municipal de 8 de marzo de 1924 fue el primero en consagrar la autonomía de los Entes locales, desde una perspectiva jurídico-formal, es incuestionable que tal Estatuto desarrolla con rigor y fidelidad el principio de autogobierno de los Municipios. Sin 
embargo, la realidad fue muy otra: el régimen político de la Dictadura transformó las prescripciones y normas estatutarias en mera "autonomía nominalista», en simple ficción legal. La Ley de Bases de 10 de julio de 1935, articulada por el Decreto de 31 de octubre del mismo año, bajo la Segunda República, estuvo dominada por la idea de eficacia de la Administración municipal, pero limitó el principio constitucional de autonomía, si bien estableció el sufragio universal igual y directo para la elección de Concejales y la designación de Alcaldes por elección directa del pueblo o por los miembros de cada Corporación. Desgraciadamente, no llegó a tener virtualidad. La Ley de Bases de Régimen local de 17 de julio de 1945 ha constituido, con modificaciones y reformas diversas, el Estatuto por el que se ha regido la Vida local española durante los últimos treinta y cinco años. Tal legislación responde a un modelo de Estado intervencionista y centralizado. La Ley de Bases del Estatuto de Régimen local de 19 de noviembre de 1975 se promulga en fecha por demás crítica. Responde, pues, a la lógica más elemental que, al entrar en abierta contradicción con la nueva configuración del Estado, fuese derogada por Ley de 7 de octubre de 1978.

La nueva Ley en elaboración parlamentaria parte del principio autonómico de que las facultades fiscalizadoras o de control son excepcionales. Por consiguiente, el control de legalidad de los actos y acuerdos de las Corporaciones locales corresponde a los Tribunales de Justicia. Sin embargo, "regula una posibilidad excepcional de actuación de la Administración del Estado o de las Comunidades Autónomas cuando una Corporación local actuara al margen del Ordenamiento constitucional o legal, incumpliendo claramente sus obligaciones $o$ atentando gravemente al interés de España. En estos casos, se establece un procedimiento de intervención, con las adecuadas garantías que permite al Gobierno o a las Comunidades Autónomas adoptar las medidas precisas para el cumplimiento forzoso de las obligaciones por parte de la Corporación o para la protección del interés general».

El segundo principio inspirador de la reforma es el carácter democrático de los órganos de gobierno de las Corporaciones locales, sancionado por el artículo 240 de la Constitución, al disponer que «los Concejales serán elegidos por los vecinos del Municipio mediante sufragio universal, igual, libre, directo y secreto", y que "los Alcaldes serán elegidos por los Concejales o por los vecinos». Aunque de forma menos explícita, el artículo 141, 2, del Texto constitucional 
también alude al carácter representativo de las Diputaciones como órganos de gobierno y administración de las Provincias. Aplica la Ley, en obediencia a la Constitución, el principio de representación político proporcional, y, en atención a él, garantiza una presencia equilibrada de los partidos políticos, coaliciones o agrupaciones electorales con representación en el Pleno, en diversos órganos colegiados de las Entidades locales. Quedan sustraídas a dicha regla las Comisiones de gobierno de los Ayuntamientos, tal vez en atención a que sólo ejercerán las facultades y competencias que les delegue el Alcalde.

El tercer principio fundamental del Proyecto es el de armonizar las Haciendas locales con las del Estado y de las Comunidades Autónomas para que la gestión económico-financiera de todo el sector público responda a criterios comunes. «En este sentido se establece que el sistema tributario local ha de basarse en los principios de capacidad económica de los contribuyentes, beneficio, localización territorial, generalidad, igualdad y progresividad, sin que ésta tenga alcance confiscatorio».

La Ley no regula el sistema tributario local-objeto, según la exposición de motivos, de un cuerpo legal complementario-, limitándose a especificar las normas generales de su funcionamiento. El artículo $78,1^{\circ}$, del capítulo dedicado a las Haciendas locales contiene bastantes normas de reenvío al decir que «las Haciendas locales se regirán: a) por la presente Ley; $b$ ) por la Ley General Tributaria; c) por la Ley del Estado que regule el sistema tributario local; d) por los reglamentos generales dictados en desarrollo de la Ley General Tributaria y por el propio de cada tributo; e) por la Ordenanza fiscal reguladora de cada tributo y que dicte la correspondiente Entidad local, de acuerdo con lo previsto en esta Ley.-2. Tendrá carácter suplementario de Ley General Presupuestaria».

\section{CONFIGURACION DE LAS ENTIDADES LOCALES}

El artículo 2. ${ }^{\circ}$ del Proyecto enumera como Entidades locales: el Municipio, la Provincia, las Islas, en los Archipiélagos Balear y Canario; las Entidades locales menores, las Mancomunidades y Agrupaciones de Entidades locales. Son también Entidades locales las Comarcas o aquellas otras Agrupaciones de Municipios limítrofes 
que puedan crear las Comunidades Autónomas, en virtud de lo dispuesto en el artículo 152, 3, de la Constitución y en sus respectivos Estatutos de Autonomia.

La Ley de Régimen local de 24 de junio de 1955 (Texto refundido) no contenía una enumeración de las Entidades locales, pero sí de las Entidades municipales. En su artículo 1. ${ }^{\circ}$, después de decir que el Estado español se halla integrado por las Entidades naturales que constituyen los Municipios agrupados territorialmente en Provincias, reconocía en el mismo artículo las Entidades locales menores. $\mathrm{Y}$ en su artículo 10 enumeraba las siguientes clases de Entidades municipales: a) el Municipio; b) la Entidad menor local; c) la Mancomunidad municipal voluntaria, y d) la Agrupación municipal forzosa. En todo su largo articulado no se hacía ninguna referencia a la Comarca. La Ley de Bases del Estatuto de Régimen local de 19 de noviembre de 1975 autorizaba en su Base 10 la constitución de Entidades comarcales, las cuales asumirían en su ámbito competencias y funciones de los Municipios integrados. Pero el Texto articulado parcial aprobado por Real Decreto de 6 de octubre de 1977 olvida esta autorización y no contiene, en consecuencia, ninguna regulación de dichas Entidades comarcales. El nuevo Proyecto de Ley básica abandona a las Comunidades Autónomas la competencia para crear Comarcas $\mathrm{u}$ «otras Agrupaciones de Municipios limítrofes» (artículo 2. ${ }^{\circ}, 2$ ), según acabamos de ver.

En razón a la posibilidad de ajustar su organización y ordenamiento a un régimen jurídico especial entre los que configura el capítulo $\mathrm{V}$ del Título primero, los artículos 28 y siguientes regulan como Entidades municipales de régimen especial: a) los Municipios con régimen de Carta; $b$ ) los Municipios en régimen de Concejo abierto; c) los Municipios inferiores a 5.000 habitantes; d) las Corporaciones metropolitanas.

En realidad, el régimen de Carta ha sido, con mayor o menor amplitud, admitido en nuestra legislación desde el Estatuto Municipal de 1924, y otro tanto puede decirse del régimen de Concejo abierto. En cuanto a los Municipios menores de 5.000 habitantes, plantean la vieja polémica de la conveniencia o no de distinguir entre Municipio urbano y Municipio rural. 


\section{ENTIDADES MUNicipales}

Acertadamente, el Proyecto elude dar una definición del Municipio, conscientes sus autores de que las definiciones responden a condensaciones de la doctrina científica y deben abandonarse a los tratadistas. A diferencia de la Ley de Régimen local de 1955 (Texto refundido), que prejuzgaba la naturaleza de los Municipios, considerándolos como Entidades naturales, el nuevo artículo $8 .^{\circ}$ se limita a considerar el Municipio como la «Entidad local básica en la que se organiza territorialmente el Estado». Y, a continuación, en el mismo artículo nos ofrece los conceptos correspondientes a las Entidades locales menores ( $\sin$ novedad respecto a su concepto tradicional) y considera también Entidades locales a las Mancomunidades municipales voluntarias y las Agrupaciones municipales forzosas, denominaciones que también conserva. Siguiendo anterior orientación, favorece la constitución de estas Entidades asociativas al decir que: «podrán gozar de subvenciones o créditos especiales, o disfrutar de una mayor participación de los tributos del Estado o de las Comunidades Autónomas, de acuerdo con lo previsto en su legislación respectiva» (art. 9.').

\section{ENTIDADES PROVINCIALES}

Es esta una materia polémica que ha generado ya un recurso de inconstitucionalidad interpuesto por acuerdo del Consejo de Ministros contra la Ley del Parlamento catalán en cuya virtud se disnuso el traspaso urgente y pleno de los servicios de las Diputaciones provinciales de su Región a la Generalidad. (El recurso fue resuelto en sentido favorable a la tesis del Gobierno.) El reconocimiento del derecho de las Regiones y Nacionalidades a constituirse en Cominidades Autónomas, al amparo de los artículos $20^{\circ}$ y 143 y siguientes de la Constitución, plantea el problema de la relación entre Provincia y Región y, consecuentemente, del reparto de competencias entre sus respectivos órganos de gobierno. La solución de la Constitución es bien clara. Su artículo 137 expresa que: «El Estado se organiza territorialmente en Municipios, en Provincias y en las Comunidades Autónomas que se constituyan. Todas estas Entidades gozan de autonomía para la gestión de sus respectivos intereses». Y el artícu- 
lo 141 toma una opción terminante al decir: «La Provincia es una Entidad local con personalidad jurídica propia, determinada por la agrupación de Municipios y división territorial para el cumplimiento de las actividades del Estado. Cualquier alteración de los límites provinciales habrá de ser aprobada por las Cortes Generales mediante Ley orgánica. El gobierno y la administración autónoma de las Provincias estarán encomendados a Diputaciones u otras Corporaciones de carácter representativo. Se podrán crear Agrupaciones de Municipios diferentes de la Provincia. En los Archipiélagos, las Islas tendrán además su administración provincial, en forma de Cabildos o Consejos".

De los preceptos transcritos se deduce claramente la subsistencia de las Provincias actuales, cuyos respectivos límites sólo podrán ser alterados mediante Ley orgánica de las Cortes. También es clara la doble naturaleza de la Provincia como Entidad local de fines propios y dotada de personalidad jurídica, determinada por la agrupación de Municipios y división territorial del Estado para la rcalización de sus propios servicios. Lo que no consagra la Constitución es el carácter inconmovible de las Diputaciones, por cuanto hace referencia a éstas «u otras Corporaciones de carácter representat:vo». El Proyecto dedica su Título segundo a las Entidades provinciales y presupone la existencia de las Diputaciones al decir simplemente que la Diputación provincial estará integrada por el Presidente y los Diputados y expresar que sus órganos serán: «El Presidente, el Pleno, la Comisión Permanente y los Vicepresidentes, en número máximo de tres. El Pleno de la Diputación podrá crear una Comisión de gobierno, cuya composición y funciones serán las mis. mas que prevén en el artículo 25 de la presente Ley para la Comisión de gobierno de los Ayuntamientos. En las Diputaciones en que funcione tal Comisión no existirá Comisión Permanente» (art. 34).

Respecto a la competencia de las Diputaciones, y aparte de la alusión tradicional al "fomento y administración de los intereses peculiares de la Provincia», el Proyecto encuadra especialmente en dicha competencia los servicios y actividades siguientes: a) Asistencia jurídica y técnica a todos los Municipios de la Provincia y, en especial, a los pequeños Municipios a que se refiere el artículo 30. b) Ordenación del territorio, gestión urbanística y promoción de viviendas. c) Construcción y conservación de la red viaria. d) Fomento de la agricultura, ganadería y riqueza forestal. e) Fomento de la 
industria. f) Difusión de la cultura; creación y sostenimiento de bibliotecas y museos. g) Protección del patrimonio cultural, monumental e histórico-artístico. h) Desarrollo del turismo. i) Construcción y mantenimiento de instalaciones deportivas. j) Defensa del medio ambiente. $k$ ) Creación y sostenimiento de establecimientos de asistencia social, sanitaria e higiene. l) Organización y sostenimiento de ferias, mercados, concursos y exposiciones. ll) Fundación de Cajas de Ahorro.

Permite también el Proyecto que los Estatutos de Autoriomía y la legislación de las Comunidades Autónomas puedan asignar a las Diputaciones competencias propias de aquéllas o delegarlas su ejercicio. Asimismo, las Comunidades Autónomas podrán atribuir a la Diputación la gestión ordinaria de los servicios de la Administración autónoma dentro del territorio de la correspondiente Provincia.

\section{Disposiciones comunes a MUNicipios y Provincias}

Siguiendo el criterio de la Ley de Régimen local de 1950-1955, el Proyecto dedica un Título (en la Ley del 50-55 era un Libro) a las disposiciones comunes, dentro del cual trata, en capítulos sucesivos, las materias siguientes: régimen administrativo; suspensión de acuerdos y ejercicio de acciones; Estatuto de las autoridades y miembros de las Corporaciones locales; Estatuto de los funcionarios al servicio de las Entidades locales; contratación; bienes, obras y servicios; régimen de intervención de las Entidades locales.

Entre estas materias comunes tiene especial relevancia la relativa al control de legalidad de los actos y acuerdos de las Corporaciones locales. "La Constitución española-dice la exposición de motivos-no sólo es explícita al proclamar la autonomía de las Entidades locales, sino al delimitar la función que corresponde a los Tribunales de Justicia en relación con la actividad de la Administración". Sobre esta última cuestión el artículo 106, 1, de la Constitución dice textualmente: "Los Tribunales controlan la potestad reglamentaria y la legalidad de la actuación administrativa...» "La Ley aplica con escrupulosidad y rigor ambos principios». Pero "tal régimen de autonomía exige, sin embargo, un cuidadoso y efe-tivo control jurisdiccional. En primer lugar, parece indispensabie la existencia de cauces y procedimientos que permitan a la Administración 
del Estado y a las Comunidades Autónomas conocer la actuación de las Entidades locales. De tal forma, podrán promover, cuando proceda, la actuación de los Tribunales mediante las oportuiras impugnaciones. También parece oportuno articular un procedimiento especial de impugnación de los actos y disposiciones de las Corporaciones locales que recaigan sobre materias de la coinpetencia $d \in l$ Estado o de las Comunidades Autónomas. En tales casos, se instrumenta un recurso especial que conlleva automáticamente la suspensión de la disposición o acto recurrido, sin perjuicio de que el Tribunal la ratifique o levante posteriormente. Por último, se regula una posibilidad excepcional de actuación del Gobierno o de las Comunidades Autónomas cuando una Corporación local actuara al margen del Ordenamiento constitucional o legal, incumpliendo claramente sus obligaciones o atentando gravemente al interés de España. En estos casos se establece un procedimiento de intervención, con las adecuadas garantías y refrendos, que permite al Gobierno o a las Comunidades Autónomas adoptar las medidas presisas para el cumplimiento forzoso de las obligaciones por parte de la Corporación o para la protección del interés general».

\section{HACIA UN TRATAMIENTO UNITARIO DEL REGIMEN ADMINISTRATIVO}

La primera de las disposiciones comunes a las Corporaciones locales es la que dispone que «sin perjuicio de las normas especiales que sean de aplicación en virtud de lo dispuesto en la presente Ley, las Entidades locales se regirán por la legislación que dicte el Estado, al amparo de lo dispuesto en el artículo 149, 1, 18, de la Constitución y en las siguientes materias: a) régimen estatutario de los funcionarios; b) procedimiento administrativo; c) expropiación forzosa; $d$ ) contratos y concesiones administrativas; $e$ ) responsabilidad administrativa» (art. 40).

La tendencia hacia un tratamiento unitario del Derecho administrativo aplicable tanto a la esfera del Estado como a las Corporaciones locales es una de las más constantes que se observan en nuestro Régimen local. Precedió a esta fase la de incluir en un mismo cuerpo legal la regulación del Derecho municipal y del Derecho provincial, que apunta ya en los Proyectos de MaUra y Canalejas, 
sufre un eclipse en los Estatutos municipal y provincial de Calvo Sotelo y en la Ley municipal de 1935 y es una realidad constante desde la Ley de Bases de Régimen local de 17 de junio de 1945, desarrollada por la Ley articulada de 1950 y el Texto refundido de 4 de junio de 1955. Posteriormente, se ha ido operando un proceso de unificación del que ha sido llamado «Derecho administrativo local» con la rama del Derecho público, que en las Facultades universitarias de Derecho y Ciencias Políticas se estudia con la denominación, ya tradicional y centenaria, de Derecho administrativo. Don Adolfo PoSADa decía que el Derecho municipal es un capítulo del Derecho político. Los administrativistas lo han tratado siempre como una rama o, si se prefiere, un capítulo del Derecho administrativo. En el antiguo Doctorado de Derecho adquirió singularidad el Derecho municipal, que después recibió en el Instituto de Estudios de Administración Local la denominación más moderna y comprensiva de Derecho de Entidades locales, cuya sustantividad han defendido algunos. Por nuestra parte, creemos sinceramente que no es una rama jurídica enteramente autónoma que hunda sus raíces en tierra propia, sino una disciplina nutrida, integrada, compuesta de diversos capítulos del Derecho público: es Derecho político la organización de las Entidades locales, el Derecho regulador del Gobierno local. Es Derecho administrativo cuanto se refiere a las funciones, obras y servicios de las Entidades locales. Es Derecho financiero la regulación de las Haciendas locales, el estudio de la fiscalidad: impuestos, tasas, contribuciones especiales, participaciones y recargos en contribuciones del Estado, etc., más la formación del Presupuesto, las Ordenanzas fiscales, la contabilidad..., etc.

En realidad, son puro Derecho administrativo la mayor parte de las normas con las que se rige el Derecho de Entidades locales, y por ello es de un gran interés estudiar el movimiento unificador que día tras día va aproximando las dos vertientes estatal y local del Derecho administrativo español. Apenas publicada la Ley articulada de Régimen local de 1950, redactada en desarrollo de la de Bases de 17 de julio de 1945, con la autonomía normativa heredada de las anteriores Leyes municipales y provinciales y, singularmente, del Estatuto municipal—de 8 de marzo de 1924-, y cuando esta autonomía lucía su esplendor en normas diferenciales de las de la Administración del Estado en materias tales como régimen jurídico, obras y servicios, expropiación forzosa, contratación, funcionarios, etc., se inicia una época de extensión al ámbito local de leyes y reglamentos 
dictados para la Administración del Estado que habrá de continuar en los años sucesivos y se refleja en la Ley de Bases del Estatuto del Régimen local. En confirmación de esta tesis podemos citar, en primer lugar, la Ley de Expropiación forzosa de 16 de diciembre de 1954. Es cierto que su artículo 85 prescribe que las expropiaciones que se lleven a cabo por razón de urbanismo y las que en cualquier caso realicen las Entidades locales se ajustarán a lo expresamente dispuesto en la Ley de Régimen local y demás aplicables, y, en lo no previsto en ellas, al contenido de la presente Ley, con lo que se da a ésta carácter meramente supletorio en la esfera de la Administración local. Pero se introduce, al propio tiempo, la modificación de que, para la determinación del justo precio, se seguirán las reglas y el procedimiento establecido en el capítulo III del Título segundo de esta Ley. En virtud de este precepto las normas para el justo precio de inmuebles a efectos de expropiación forzosa contenidos en el artículo 149 del Texto refundido de la Ley de Régimen local de 24 de junio de 1955 (reproducido literalmente del Texto articulado de 1950) perdieron su vigencia desde la entrada en vigor de la citada Ley de Expropiación forzosa de 1954 y, por tanto, desde antes de la publicación del expresado Texto refundido de 1955. Por lo demás, en la repetida Ley de Expropiación forzosa de 1954 se hacen continuas referencias a las facultades expropiatorias del Estado, la Provincia y el Municipio, por lo que puede afirmarse que progresa la tendencia al tratamiento unitario de dicho instrumento jurídico de socialización, de subordinación del interés privado al público, cualquiera que sea la esfera de la Administración pública a que haya de aplicarse.

En cuanto al procedimiento administrativo, el Reglamento de Organización, Funcionamiento y Régimen Jurídico de las Corporaciones locales, en su artículo 258, dice: "Las Corporaciones locales podrán aprobar Reglamentos de procedimiento administrativo para la tramitación de sus asuntos, siempre que no contradigan las normas fundamentales del presente capítulo». El artículo 322 expresa: "para lo previsto en el presente capítulo regirán como supletorias las normas del Reglamento de Procedimiento Administrativo del Ministerio de la Gobernaciónn.

Es decir, que se establecen tres órdenes de normas: las prescripciones autonómicas de las Corporaciones locales, en cuanto no estén en oposición con las generales del Reglamento; las contenidas en 
éste, y, como supletorias de las mismas, las del Reglamento de Procedimiento del expresado Departamento ministerial.

Otra materia, próxima a la que veníamos tratando y que denota esta tendencia a la regulación en un mismo cuerpo legal de las instituciones y actividades administrativas del Estado y de las Corporaciones locales, la encontramos en la Ley de la Jurisdicción Contencioso-administrativa de 27 de diciembre de 1956. En su preámbulo leemos estas reveladoras palabras: "Al referirse la Ley a la Administración lo hace en los términos más amplios y comprensivos. Por tal entiende, desde luego, la Administración territorial del Estado y de las Entidades locales. Pero también las demás Corporaciones e Instituciones públicas sometidas a la tutela de aquéllas». Y, en efecto, el artículo $1 .^{\circ}$ de la Ley, después de decir que la Jurisdicción contencioso-administrativa conocerá de las pretensiones que se deduzcan en relación con los actos de la Administración pública sujetos al Derecho administrativo y con las disposiciones de carácter inferior a la Ley, puntualiza que «se entenderá a estos efectos por Administración pública: a) La Administración del Estado en sus diversos grados. b) Las Entidades que integran la Administración local; y c) Las Corporaciones e Instituciones públicas sometidas a la tutela del Estado o de alguna Entidad local». Su Disposición final dice así: "Quedan derogadas las disposiciones legales y reglamentarias relativas a la jurisdicción y procedimiento contencioso-administrativo, así como las reguladoras del procedimiento administrativo, en cuanto se opongan a la presente Ley".

Respecto a los funcionarios locales, el criterio actual de acomodación al régimen de los funcionarios del Estado, inesperadamente, se inicia con la Ley 48 de 23 de julio de 1966, sobre modificación parcial del Régimen local, al expresar en su Disposición final segunda que «el Gobierno, en el plazo de un año, contado a partir de la fecha de entrada en vigor de esta Ley, a propuesta conjunta de los Ministerios de Hacienda y de la Gobernación, y con informe de la Comisión Superior de Personal, remitirá a las Cortes un Proyecto de Ley acomodando el régimen y retribución de todos los funcionarios al servicio de las Corporaciones locales a directrices y normas aplicables a los funcionarios civiles del Estado, atendiendo a las peculiaridades de sus respectivas funciones».

Esta línea de aplicación de criterios unitarios en la regulación del régimen jurídico y económico de los funcionarios públicos, cual- 
quiera que sea la esfera de la Administración a que pertenezca, se afianza definitivamente en la Ley 79 de 1968, sobre Bases para la acomodación del régimen y retribuciones de los funcionarios de Administración local a los de la Administración civil del Estado.

Esta tendencia hacia un tratamiento unitario del Derecho administrativo aplicable a la esfera del Estado y a la de las Entidades locales estaba bien claramente expresada en el anteproyecto remitido por el Ministerio de Administración Territorial al Gobierno y que éste acordó enviar a la Dirección General de lo Contencioso del Estado, al limitarse a decir en su artículo 51, primero de los constitutivos de las disposiciones comunes a las Corporaciones locales (Título tercero), que en las materias que mencionaba-y que son las mismas que hoy enumera el transcrito artículo 40 del Proyecto: funcionarios, procedimiento administrativo, etc.- las Entidades locales se regirán por la legislación que dicte el Estado, salvando sólo las normas especiales aplicables de la presente Ley». Pero el actual artículo 40 manda aplicar, al mismo tiempo, «la legislación que dicten las Comunidades Autónomas, de acuerdo con lo establecido en las Leyes del Estado y en sus respectivos Estatutos». De este modo se ha desvirtuado la intención unificadora del Proyecto al admitirse la posibilidad de una diversidad de normas procedentes unas del Estado y otras de las Comunidades Autónomas.

\section{CONCLUSION}

Por primera vez se presenta a las Cortes un Proyecto de Ley de Régimen local que previene la regulación de algunas de las materias que éste debiera contener por los órganos legislativos correspondientes de las «Comunidades Autónomas». Corresponde también a éstas desarrollar la parte del articulado del Proyecto limitada a esbozar normas o a establecer unas líneas de carácter programático. Es compleja la distribución de competencias entre el Estado, las Comunidades Autónomas y las propias Entidades locales en el ejercicio de sus facultades autonómicas.

La estructura del Proyecto no se aparta sustancialmente de la establecida en la Ley de Régimen local de 1950-55. Abandona el ca- 
rácter autoritario que late en ésta para reconstruir el carácter democrático que inspiraba el Estatuto municipal y la Ley de 1935 (ni en uno ni en otra llevados a la práctica). Y en orden a funciones y servicios, contiene escasas novedades respecto a la legislación anterior. 